\title{
Pemanfaatan Minyak Biji Alpukat (Persea americana Mill) sebagai Bahan Baku Pembuatan Biodiesel dengan Pemurnian Water Washing
}

\author{
Risse Entikaria Rachmanita ${ }^{1)}$, Ayu Safitri ${ }^{1)}$ \\ ${ }^{1)}$ Program Studi Teknik Energi Terbarukan, Jurusan Teknik, Politeknik Negeri Jember \\ risse_rachmanita@polije.ac.id
}

(Article History: Received 08-04-2020; Accepted 06-07-2020; Published 07-07-2020)

\begin{abstract}
ABSTRAK
Biodiesel merupakan bahan bakar alternatif yang berasal dari bahan bakar nabati dan hewani yang tergolong dapat diperbarui. Bahan nabati yang dapat digunakan sebagai bahan baku contohnya seperti biji alpukat. Biji alpukat yang melalui proses pengepresan menghasilkan minyak dan getah (gum). Proses degumming dilakukan untuk memisahkan minyak dan getah dengan menggunakan asam phospat $0,5 \% \mathrm{v} / \mathrm{v}$. Kandungan FFA dapat digunakan pada proses transesterifikasi untuk menghasilkan metil ester dengan perbandingan minyak dan metanol serta lama waktu transesterifikasi. Penelitian ini bertujuan untuk mengetahui pengaruh perbandingan minyak dan metanol serta pengaruh waktu terhadap rendemen biodiesel dan menentukan karakteristik biodiesel yang dihasilkan sesuai dengan standar SNI 04-7182-2015. Penelitian ini dirancang dengan menggunakan metode Rancang Acak Lengkap (RAL) dengan 2 faktorial yaitu perbandingan minyak dan metanol (1:4, 1:6, 1:8) dan lama waktu transesterifikasi yaitu (30 menit, 60 menit, 90 menit). Parameter karakteristik biodiesel yang dianalisis meliputi densitas, viskositas, bilangan asam, angka setana, nilai kalor, angka iodin dan kadar metil ester yang sesuai dengan SNI 04-71822015. Hasil penelitian menunjukkan bahwa rendemen tertinggi terdapat pada sampel A3T1 (perbandingan 1:8 dengan lama waktu transesterifikasi 30 menit). Hasil pengujian mutu A3T1 yaitu densitas $968 \mathrm{~kg} / \mathrm{m}^{3}$, viskositas $4,6037 \mathrm{~mm}^{2} / \mathrm{s}$, bilangan asam $0,4 \mathrm{mgKOH} / \mathrm{gr}$, angka setana 44,77 , nilai kalor 48,81 MJ/kg, angka iodine 8,10 gram/100gram dan kadar metal ester 94,05\%.
\end{abstract}

Kata kunci: Biji alpukat; biodiesel; pemurnian

\section{Utilizing Avocado Seed Extraction (Persea americana Mill) as Bioidesel Raw Material by Purifying Water Washing}

\begin{abstract}
Biodiesel is an alternative fuel derived from vegetable and animal fuels that is classified as renewable resource. Vegetable materials that can be used as raw materials for example are avocado seeds. Through the pressing process, avocado seeds will produce oil and gum. The degumming process is carried out to separate the oil and the gum using $0.5 \% \mathrm{v} / \mathrm{v}$ phosphoric acid. FFA content can be used in the transesterification process to produce methyl esters with a ratio of oil and methanol and the length of transesterification time. This research aims to determine the effect of the ratio of oil and methanol as well as the effect of time on the yield of biodiesel and to determine the characteristics of biodiesel in accordance with SNI 04-7182-2015 biodiesel standards. The research was designed using Complete Randomized Design (CRD) method with 2 factorial comparisons of oil and methanol $(1: 4,1: 6,1: 8)$ and the length of transesterification time (30 minutes, 60 minutes, 90 minutes). The analyzed parameters of biodiesel characteristics include density, viscosity, acid number, cetane number, calorific value, iodine number and metal ester content in accordance with the Indonesian National Standard number 04-7182-2015. The results showed that the highest yield was in the A3T1 sample (1:8 ratio with 30 minutes transesterification time). A3T1 quality test results showed the density of $968 \mathrm{~kg} / \mathrm{m}^{3}, 4.6037 \mathrm{~mm}^{2} / \mathrm{s}$ viscosity, 0.4 $\mathrm{mgKOH} / \mathrm{gr}$ acid number, 44.77 cetane number, $48.81 \mathrm{MJ} / \mathrm{kg}$ calorific value, 8.10 gram $/ 100 \mathrm{gram}$ iodine number and $94.05 \%$ of ester metal content.
\end{abstract}

Keywords: Avocado seed; biodiesel; purification 


\section{PENDAHULUAN}

Bahan bakar minyak bumi merupakan salah satu sumber energi yang utama dan menjadi kebutuhan primer dalam kehidupan sehari-hari. Sumber bahan bakar minyak bumi tersebut adalah fosil yang membutuhkan waktu lama dalam pembentukannya (Ritonga et al., 2013). Hampir 80\% kebutuhan energi dunia saat ini dipenuhi oleh bahan bakar fosil seperti minyak, gas, dan batu bara. Perkiraan beberapa tahun ke depan cadangan minyak bumi dari fosil akan habis sehingga dibutuhkan bahan bakar alternatif yang dapat diperbarui untuk mengganti minyak bumi tersebut (Tamako, 2017).

Biodiesel merupakan bahan bakar alternatif yang dapat diperbarui dengan komposisi asam lemak yang terdiri dari minyak nabati maupun minyak hewani (Arifin et al., 2016). Biodiesel juga merupakan bahan bakar yang ramah lingkungan yang tidak mempunyai efek terhadap kesehatan yang dapat dipakai sebagai bahan bakar kendaraan bermotor yang dapat menurunkan emisi bila dibandingkan dengan minyak diesel (Rachmanita et al., 2018; Meisandi, 2013). Biodiesel terbuat dari minyak nabati yang berasal dari sumber daya alam yang dapat diperbaharui. Bahan baku yang berpotensi sebagai bahan baku pembuat biodiesel antara lain kelapa sawit, kedelai, jarak pagar, alpukat dan beberapa jenis tumbuhan lainnya (Rachmanita, 2019; Risnoyatiningsih, 2012).

Biji alpukat merupakan limbah yang dibuang setelah memanfaatkan daging buahnya yang memiliki banyak kelebihan mulai dari kandungan lipidnya yang sangat tinggi yang digunakan hanya sebagai kosmetik dan obat-obatan. Pemanfaatan biji alpukat saat ini hanya sebagai obat penghilang stress saja dan belum dimanfaatkan untuk yang lainnya padahal biji alpukat memiliki kandungan fatty acid methyl ester sebagai bahan pembuat biodiesel. Selain itu, kandungan minyak biji alpukat lebih tinggi dibanding tanaman biji-bijian namun masih lebih rendah dari minyak kelapa sawit (Rachmanita, 2019; Risnoyatiningsih, 2012).

Tanaman alpukat banyak ditanam di Indonesia, hal ini tentu saja menjamin ketersediaan biji dari buah alpukat sebagai bahan baku pembuatan minyak nabiati. Dari data Badan Pusat Statistika (2018) produksi buah alpukat di Indonesia pada tahun 2018 adalah 410.094 ton (Badan Pusat Statistik, 2019)dan jumlahnya terus meningkat dari tahun ke tahun, sedangkan jumlah minyak nabati yang dapat diambil dari biji alpukat cukup tinggi yaitu antara 3-30\% tergantung pada sifat ekologis dan ras dari tanaman tersebut.

Salah satu bagian dari proses biodiesel yang tidak kalah pentingnya adalah pemurnian metil ester menjadi biodiesel. Pencucian adalah proses menghilangkan sisa metanol, sisa katalis, sabun dan gliserol yang tidak bisa dihilangkan pada proses pemisahaan sebelumnya menggunakan corong pemisah. Metode yang umum digunakan dalam pemurnian biodiesel adalah water washing yaitu pencucian menggunakan air. Proses pencucian water washing dilakukan hingga tiga kali untuk menghilangkan sisa gliserol, metanol yang tidak bereaksi, katalis dan sabun yang terbentuk selama proses pembentukan metil ester (Rejeki, 2009) . Metode water washing memiliki kelemahan yaitu membutuhkan waktu proses yang lama (dapat mencapai 2,5 jam), membutuhkan air dalam jumlah besar, dan menghasilkan limbah berupa emulsi sabun, gliserol, methanol yang bereaksi, katalis dalam jumlah yang besar yang tidak dapat dibuang begitu saja ke lingkungan sedangkan kelebihan dari pencucian ini ialah mudah dan murah diterapkan dalam pencucian biodiesel (Hartono, 2014). Jumlah limbah cair yang diproduksi sekita 30\% dari jumlah biodiesel yang dihasilkan. Selain itu metode ini harus dilanjutkan dengan proses drying untuk menguapkan air sisa pencucian yang terkandung didalam biodiesel sehingga diperlakukan inovasi teknologi baru yang dapat mengatasi masalah tersebut. Penelitian ini bertujuan untuk mengetahui pengaruh perbandingan minyak dan metanol serta pengaruh waktu terhadap rendemen biodiesel dan menentukan karakteristik biodiesel yang dihasilkan sesuai dengan standar SNI 047182-2015.

\section{METODE PENELITIAN}

Penelitian ini dilaksanakan di Laboratotium Teknik Energi Terbarukan Politeknik Negeri Jember. Penelitian ini dilaksanakan pada Bulan Mei-September 2019. 
Alat-alat yang digunakan dalam penelitian ini yaitu buret, erlemeyer, statif, pipet tetes, hot plate, magnetic stirrer, breaker glass, gelas ukur, piknometer, corong pemisah, neraca analitik, thermometer, labu takar, kertas saring. Bahan-bahan yang digunakan dalam penelitian ini yaitu minyak biji alpukat, $\mathrm{H}_{2} \mathrm{SO}_{4}, \mathrm{KOH}$, metanol, fenolftalein, etanol 97\%, akuades, aluminium oil.

Penelitian ini dilakukan dua tahapan yaitu penelitian pendahuluan dan penelitian utama. Dengan uraian seagai berikut:

\section{Penelitian Pendahuluan}

Penelitian pendahuluan dilakukan untuk mempersiapkan alat dan bahan serta pengepresan biji alpukat untuk mengetahui karakteristik minyak biji alpukat sebelum dilakukan proses pembuatan biodiesel dari minyak biji alpukat. Karekteristik minyak biji alpukat meliputi kandungan asam lemak bebas, bilangan asam, viskositas, dan densitas dengan metode piknometer.

Sebelum dilakukan karakteristik, biji yang telah dikumpulkan dicuci terlebih dahulu agar mengurangi bau tidak sedap karena sisa daging alpukat yang masih menempel akibat didiamkan cukup lama. Biji alpukat yang sudah dicuci bersih kemudian dijemur di bawah terik sinar matahari selama kurang lebih 2-3 hari. Biji alpukat yang telah dijemur, dimana kondisi biji alpukat tidak boleh terlalu kering dan terlalu basah karena akan mempengaruhi hasil dari minyak saat pengepresan. Biji alpukat kemudian dipotong kecil-kecil tujuannya untuk mempermudah saat proses pengepresan.

Pengepresan biji alpukat dilakukan secara manual menggunakan mesin pres hidrolik. Mesin pres tersebut dikontrol oleh pegas dan pengunci. Biji alpukat yang sudah dipotong kecil - kecil dimasukkan kedalam kain penyaring yang kemudian dimasukkan kedalam mesin press. Kain penyaring disini bertujuan untuk menahan biji agar tidak keluar saat dipres sehingga tidak tercampur dengan minyak. Pengepresan dilakukan pengulangan 2 kali untuk hasil yang maksimal, dimana hasil minyak dipengaruhi oleh tekanan yang diberikan saat pengepresan.

Selanjutnya pretreatment atau degumming merupakan proses awal yang harus dilakukan agar hasil biodiesel dapat maksimal. Proses ini bertujuan untuk menghilangkan getah dan bau pada minyak biji alpukat. Proses degumming dilakukan untuk memisahkan minyak dari kotorankotoran yang berupa gum, protein, fosfolipid, dan lain (Pratiwi et al., 2016). Minyak biji alpukat dipanaskan pada suhu $90^{\circ} \mathrm{C}$, kemudian ditambahkan asam phospat $0.5 \%$ dari berat minyak sambil terus diaduk dengan menggunakan magnetic stirrer salama 30 menit. Kemudian minyak tersebut dimasukkan ke dalam corong pisah, didiamkan selama 24 jam selanjutnya dipisahkan. Minyak biji alpukat hasil degumming kemudian dilakukan karakteristik minyak meliputi seperti kandungan FFA dan bilangan asam.

\section{Penelitian Utama}

Variasi perlakuan yang dilakukan pada penelitian utama adalah perbandingan metanol dan minyak serta waktu terhadap rendemen biodiesel dan menentukan karakteristik biodiesel yang dihasilkan sesuai dengan standar SNI 04-7182-2015. Perbandingan 1:4 pada waktu 30 menit merupakan titik nyala terbaik, sedangkan perbandingan 1:8 pada waktu 90 menit merupakan pengujian titik tuang terbaik (Risnoyatiningsih, 2012).

Pencucian dilakukan untuk memisahkan biodiesel dari sisa-sisa katalis dan gliserol sehingga didapatkan biodiesel murni. Pencucian yang dilakukan pada penelitian ini menggunakan water washing. Proses pencucian dilakukan sebanyak 3 kali hingga larutan di bagian bawah berwarna lebih jernih atau lapisan paling bawah sesuai dengan yang dikehendaki tahap selanjutnya yaitu pemanasan biodiesel.

\section{Parameter Penelitian}

Parameter yang digunakan untuk mengetahui hasil dan kualitas biodiesel yang diperoleh yaitu :
a. Rendemen Biodiesel
Rendemen biodiesel dihitung dengan tujuan mengetahui perbandingan terbaik menggunakan rumus sebagai berikut :

Rendemen $(\%)=$ (Massa biodiesel setelah pencucian $(\mathrm{g}) /$ (Massa minyak biji alpukat (g))x $100 \%$

b. Karakter Biodiesel Sesuai SNI 04-71822015

Parameter yang akan digunakan berdasarkan karakter biodiesel sesuai SNI 047182-2015 yang telah ditentukan yaitu: nilai 
FFA, densitas, kadar metil ester (FAME), bilangan asam, nilai kalor, angka setana.

Pengujian nilai FFA dilakukan sesuai standart AOAC 1984 dengan mengambil $9 \mathrm{ml}$ etanol $97 \%$ dicampur dengan $3 \mathrm{ml}$ sampel biodiesel dan dimasukkan dalam erlenmeyer. Kemudian dilakukan pemanasan selama 10 menit dan ditambahkan 3 tetes indikator PP. Kemudian dilakukan titrasi pada campuran larutan tersebut dengan menggunakan $\mathrm{KOH}$ 0,1 M hingga berubah warna menjadi merah muda dan warna tersebut harus bertahan selama 15 detik. Data yang diperoleh dapat dihitung menggunakan rumus sebagai berikut (Salamah, 2017):

$\mathrm{FFA}=($ volume $\mathrm{KOH}(\mathrm{ml}) \times \mathrm{M} \mathrm{KOH} \times \mathrm{Mr}) /(10$

$\mathrm{X}$ Massa sampel)

Dengan $\mathrm{Mr}=$ Molekul relatif asam lemak yang paling banyak dalam minyak.

Pengujian densitas sesuai dengan standart ASTM D 1298 menggunakan metode piknometer. Tahap pertama menimbang massa pikno kosong. Kemudian memanaskan biodiesel sampai suhu mencapai $40^{\circ} \mathrm{C}$. Selanjutnya memasukkan biodiesel tersebut ke dalam piknometer sampai penuh dan ditutup, kemudian menimbang massanya. Menurut (Enweremadu \& Alamu, n.d.) data yang didapatkan dapat dihitung menggunakan rumus sebagai berikut :

$$
\rho=\left(m_{2}-m_{1}\right) / v
$$

dengan

$\rho=\operatorname{densitas}(\mathrm{g} / \mathrm{ml})$

$\mathrm{m}_{2}=$ massa pikno + bahan $(\mathrm{g})$

$\mathrm{m}_{1}=$ massa pikno kosong $(\mathrm{g})$

$\mathrm{v}=$ volume piknometer kosong $(\mathrm{ml})$

Analisis kadar metil ester dilakukan dengan menggunakan perhitungan pendekatan nilai viskositas dengan rumus pendekatan sebagai berikut (Enweremadu and Alamu, n.d.):

$\%$ FAME $=-45,055$ (Viskositas Kinematik) + 162,85

Analisis bilangan asam dilakukan menggunakan standart AOAC 1984 dengan cara mengambil $3 \mathrm{ml}$ sampel biodiesel dicampur dengan $9 \mathrm{ml}$ etanol 97\%. Campuran tersebut dipanaskan hingga mencapai suhu $45^{\circ} \mathrm{C}$ dan menambahkan indikator pp 3 tetes. Selanjutnya campuran tersebut dilakukan titrasi menggunakan $\mathrm{KOH} \quad 0,1 \mathrm{M}$ hingga warna berubah menjadi merah muda dan bertahan 15 detik. Data yang diperoleh selanjutnya dapat dihitung menggunakan rumus sebagai berikut (Enweremadu and Alamu, n.d.):

Bilangan asam $=(56,1 \times \mathrm{M} \mathrm{KOH} \times$ volume $\mathrm{KOH}(\mathrm{ml})) /($ Massa Sampel ).

Perhitungan nilai kalor suatu biodiesel dilakukan dengan menggunakan rumus pendekatan nilai bilangan penyabunan dan bilangan iodin dari biodiesel tersebut (Enweremadu and Alamu, n.d.):

$\mathrm{HHV}=49,43-(0,015 x$ bilangan iodin $)-$ ( $0,041 \mathrm{x}$ bilangan penyabunan $)$

Pengukuran angka setana menggunakan nilai pendekatan indeks setana. Rumus pendekatan yang digunakan oleh adalah sebagai berikut (Enweremadu and Alamu, n.d.):

Indeks setana $=46,3+5,458 /$ (bilangan penyabuhan $) \quad-(0,225 \quad \mathrm{x}$ Bilangan

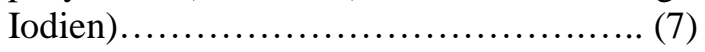

\section{Analisis Data}

Pada penelitian ini menggunakan Rancangan Acak Lengkap (RAL) dengan 2 faktorial 2 kali pengulangan pada reaksi transesterifikasi. Faktor pertama adalah perbandingan methanol dan minyak terdiri dari 3 taraf yaitu 1:4, 1:6, 1:8 dan faktor yang kedua adalah waktu transesterifikasi yang terdiri dari 3 taraf yaitu 30 menit, 60 menit, 90 menit.

Data yang diperoleh dari penelitian kemudian dianalisa menggunakan uji $\mathrm{F}$ Analysis of variance (ANOVA) untuk mengetahui perbandingan methanol dan minyak serta pengaruh waktu. Jika non signifikan maka FHitung< FTabel 0,05 dan jika sangat signifikan maka FHitung > FTabbel 0,01. Namun jika antar perlakuan terjadi perbedaan yang signifikan (berbeda nyata) dengan ketentuan FHitung diantara FTabel 0,05 dan FTabel 0,01, maka dilanjutkan dengan uji wilayah berganda Ducan (Duncan's Multiple Range test) dengan taraf error $1 \%$ dan $5 \%$. 


\section{HASIL DAN PEMBAHASAN}

\section{Hasil Penelitian Pendahuluan}

a. Pengepresan Biji Alpukat

Hasil pengepresan pada minyak biji alpukat masih tercampur dengan kandungan air dan getah sehingga perlu pretreatment selanjutnya. Hasil minyak biji alpukat dipengaruhi oleh jenis biji alpukat serta daerah tumbuhnya biji tersebut. Minyak biji alpukat hasil pengepresan saat didiamkan beberapa waktu seperti mengandung gas karena saat dibuka mengeluarkan suara seperti gas dan menyebabkan wadah atau botol tersebut keras dikarenakan ada udara yang terperangkap didalam botol.

b. Degumming Minyak Biji Alpukat

Minyak biji alpukat hasil pengepresan kemudian dipanaskan pada suhu $90^{\circ} \mathrm{C}$, kemudian ditambah larutan asam phosphat sebanyak $0,5 \%$ dari berat sampel sambil terus diaduk dan dicampur menggunakan magnetic stirrer selama 30 menit. Minyak biji alpukat yang telah dicampur larutan asam phosphat selama 30 menit kemudian dituangkan ke dalam corong pemisah dan didiamkan selama 24 jam atau sampai terbentuk dua lapisan. Lapisan bawah adalah getah dan lapisan teratas adalah minyak murni biji alpukat yang kemudian digunakan sebagai bahan biodiesel.

\section{c. Kadar FFA Minyak Biji Alpukat}

Pada Tabel 1 ditunjukkan hasil pengukuran FFA minyak biji alpukat yang dibandingkan dengan hasil pengukuran penelitian terdahulu.

Tabel 1. Hasil Pengukuran Kadar FFA

\begin{tabular}{clc}
\hline No & \multicolumn{1}{c}{ Keterangan } & Kadar FFA (\%) \\
\hline 1 & Penelitian ini (2019) & 0,68 \\
2 & Djenar (2012) & 1,03 \\
3 & Rachimoellah (2009) & $0,36-0,82$ \\
4 & Sihombing (2016) & 0,64 \\
\hline
\end{tabular}

Perbandingan kadar FFA dengan penelitian terdahulu bertujuan untuk mengetahui bahwa bahan baku minyak biji alpukat sebagai bahan baku biodiesel mempunyai kadar FFA yang berbeda. Perbedaan ini disebabkan oleh tempat dimana buah alpukat tersebut tumbuh, jenis biji alpukat selain itu juga dipengaruhi oleh cara ektraksi minyak biji alpukat dan lamanya proses penjemuran biji alpukat tersebut.

Penelitian ini menggunakan biji alpukat yang berasal dari penjual jus di daerah Bangkalan dimana biji tersebut memang dikumpulkan dan diperjualbelikan. Menurut The National Biodiesel Foundation (NBF) (1994) yang menyebutkan bahwa alpukat mengandung lemat nabati yang tersusun dari senyawa alkil ester dengan komposisi yang sama dengan bahan bakar diesel.

Hasil analisis penelitian menunjukkan bahwa minyak biji alpukat mengandung kadar FFA sebesar $0,87 \%$ sehingga tidak perlu dilakukan proses esterifikasi dikarenakan kandungan FFAnya kurang dari 2\% sehingga dapat dilanjutkan ke proses transesterifikasi.

\section{Hasil Penelitian Utama}

a. Transesterifikasi

Proses reaksi transesterifikasi dengan memanaskan minyak biji alpukat dengan suhu $55^{\circ}-60^{\circ} \mathrm{C}$. Pemanasan dilakukan dengan cara diaduk menggunakan magnetic stirrer dengan kecepatan $700 \mathrm{rpm}$, disaat suhu sudah mencapai $55-60^{\circ} \mathrm{C}$ maka tambahkan larutan metoksida secara bertahap dan perlahan. Larutan metoksida tersebut terdiri dari katalis $\mathrm{KOH} 1 \% \mathrm{~m} / \mathrm{v}$ dan metanol dimana penelitian ini menggunakan perbandingan metanol mulai dari 1:4 dengan metanol sebesar 55,40 ml, 1:6 dengan metanol 86,37 $\mathrm{ml}$ dan 1:8 dengan metanol sebanyak $110,78 \mathrm{ml}$. Perbandingan metanol tersebut bertujuan untuk mengetahui pengaruh terhadap hasil biodiesel dan rendemennya. Katalis yang digunakan merupakan katalis basa karena reaksi tersebut transesterifikasi lebih cepat dengan katalis basa daripada katalis asam (Atadashi, 2015). Konsentrasi katalis sebanyak $1 \%$ reaksi dapat dikatakan berjalan optimal dan menghasilkan rendemen yang tinggi (Aziz et al., 2017). Suhu reaksi dijaga pada suhu $55-60^{\circ} \mathrm{C}$, karena suhu kurang dari $55^{\circ} \mathrm{C}$ akan mempengaruhi rendemen dari biodiesel sedangkan suhu lebih dari $60^{\circ} \mathrm{C}$ metanol akan menguap dan mempengaruhi reaksi tersebut. Gambar 1 dibawah ini menunjukkan proses pemisahan transesterifikasi.

Hasil transesterifikasi berupa metil ester, sedangkan hasil sampingnya berupa gliserol. Memisahkan antara biodiesel atau metil ester dengan gliserol perlu adanya proses pengendapan dalam corong pemisah selama kurang lebih 8 jam atau sampai terbentuk dua 
lapisan. Proses pemisahan gliserol berada dibagian bawah sedangkan metil ester atau biodiesel kasar berada dibagian atas. Produk utama memiliki warna yang lebih cerah dibandingkan warna gliserol atau produk samping. Gliserol yang dihasilkan pada setiap perbandingan berbeda semakin banyak perbandingan metanol dan waktu separasi membuat gliserol semakin pekat atau gelap. Contohnya seperti gliserol hasil perbandingan 1:4 dan 1:6 dimana hasil gliserolnya perbandingan 1:4 warnanya lebih cerah dibanding gliserol 1:6. Hasil gliserol setelah diseparasi juga menghasilkan volume yang berbeda semakin banyak perbandingan minyak dan larutan metoksida akan menghasilkan gliserol yang semakin banyak.

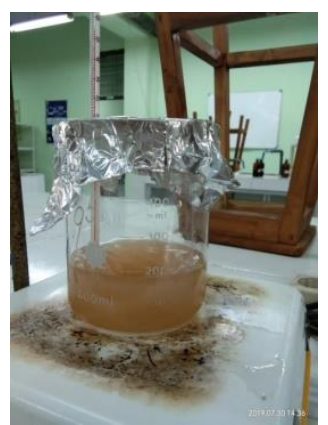

(a)

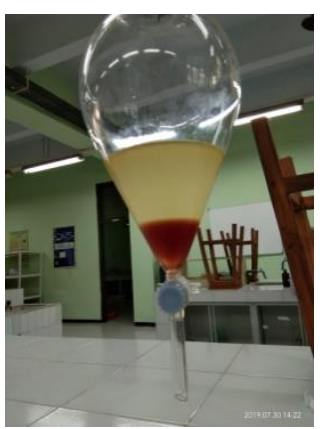

(b)
Gambar 1. Proses Transesterifikasi: (a) Proses Pencampuran Minyak dan Metanol, (b) Proses Pemisahan

\section{b. Proses Pencucian Water Washing}

Pencucian biodiesel water washing menggunakan akuades yang dipanaskan bersuhu $60-70^{\circ} \mathrm{C}$ sebanyak $50 \%$ v/v saat akuades mendidih kemudian dituang ke dalam corong pemisah yang kemudian dikocok hingga akuades dan minyak homogen. Didiamkan hingga terbentuk tiga lapisan dimana lapisan paling bawah adalah air kemudian lapisan kedua adalah campuran minyak dan air dan lapisan paling atas adalah biodiesel. Proses pencucian diulang sebanyak 3 kali hingga larutan di bagian bawah berwarna lebih jernih atau lapisan paling bawah sesuai dengan yang dikehendaki tahap selanjutnya yaitu pemanasan biodiesel.

Pencucian pada sampel perbandingan 1:4 (minyak:metanol) mengalami perbedaan reaksi, dimana saat akuades dituang ke dalam sampel dan dikocok hingga homogen saat diseparasi hanya terdapat 2 lapisan pada pencucian pertama. Dua lapisan tersebut hanya minyak di bagian atas dan di bagian bawah berwarna putih susu yang seharusnya bening seperti air, sehingga membutuhkan waktu yang lebih lama dibanding sampel lain. Lapisan terbawah yang berupa air dibuang. Berbeda dengan hasil pencucian sampel lainnya, sampel 1:4 berupa seperti jelly dan sedikit kental. Pencucian kedua pun tidak jauh berbeda dengan pencucian pertama, namun pada pencucian ketiga setelah diseparasi terdapat tiga lapisan dengan cukup memakan waktu lama. Perbandingan separasi atau pemisahan di antara sampel, hanya perbandingan 1:4 yang membutuhkan waktu lama sekitar 45 menit lebih lama dibanding sampel lainnya. Proses pemisahaan saat water washing seperti pada Gambar 2(a). Salah satu faktornya saat transesterifikasi proses pemanasannya hanya 30 menit yang kemungkinan menyebabkan minyak dan larutan metoksida tidak cukup homogen dan terjadinya penyabunan saat pencucian. Terbukti pada sampel 1:6 dan 1:8 yang memiliki waktu lebih lama saat transesterifikasi tidak mengalami kendala saat pencucian.

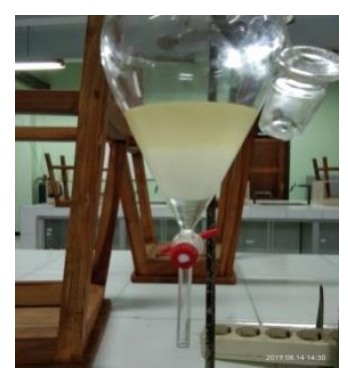

(a)

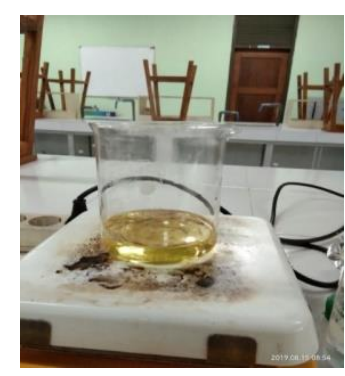

(b)
Gambar 2. Proses Pencucian Water Washing: (a) Proses Pemisahaan saat Pencucian, (b) Proses Pemanasan setelah Dicuci

Pada Gambar 2 (b) memperlihatkan proses pemanasan biodiesel setelah tahap pencucian. Pemanasan biodiesel dilakukan untuk menghilangkan sisa air yang masih terkandung dalam biodiesel. Pemanasan biodiesel dilakukan dengan menggunakan $\mathrm{Hot}$ plate dengan suhu $110^{\circ} \mathrm{C}$ dengan putaran motor 200 rpm selama kurang lebih 30 menit hingga tidak ada letupan. Putaran motor pada Hot plate tidak boleh melebihi $200 \mathrm{rpm}$ dikarenakan putaran yang tinggi akan menghasilkan emulsi seperti adanya asap yang 
keluar saat pemanasan. Proses pemisahan biodiesel dengan air akan mengakibatkan penurunan kualitas biodiesel (Ritonga et al., 2013).

Biodiesel kasar yang sudah dicuci kemudian disimpan dibotol kaca, namun dari 18 sampel biodiesel terdapat beberapa sampel yang dibagian dasar atau bawah botol terdapat endapan putih diantaranya yaitu sampel perbandingan 1: 4 dengan waktu 30 menit dan 90 menit. Penyaringan dilakukan menggunakan kertas saring dengan cara beaker glass yang diberi kertas saring kemudian sampel dituangkan hingga benarbenar hanya biodiesel yang berada di beaker glass. Biodiesel yang sudah dilakukan penyaringan kemudian dituang kembali ke botol sesuai nama sampel. Endapan yang sudah tersaring bertekstur seperti jelly. Penyebab terjadinya endapan mungkin dikarenakan proses penyabunan saat pencucian masih terkandung dalam biodiesel atau disaat pencucian kurang bersih dan masih ada zat pengotor yang masih tersisa.

\section{Randemen Biodiesel Minyak Biji Alpukat}

Rendemen biodiesel merupakan hasil presentase dari perbandingan jumlah biodiesel setelah pencucian dengan jumlah minyak biji alpukat yang digunakan diawal proses. Tingginya nilai rendemen dapat dipengaruhi beberapa hal. Faktor yang mempengaruhi rendemen biodiesel diantaranya yaitu jenis dan jumlah katalis yang digunakan, lamanya waktu reaksi, suhu dan proses pencucian dari biodiesel kasar. Nilai rendemen biodiesel tertinggi pada penelitian ini dapat diketahui dengan menggunakan Analisis Rancang Acak Lengkap (RAL) menggunakan dua faktor. Faktor pertama yaitu fakor perbandingan metanol dengan minyak yang terdiri dari tiga taraf ialah 1:4, 1:6, 1:8. Faktor yang kedua yaitu waktu reaksi transestrifikasi yaitu 30 menit, 60 menit, dan 90 menit.

Berikut adalah data grafik rendemen biodiesel minyak biji alpukat menggunakan perlakuan perbandingan minyak dan metanol serta pengaruh waktu transesterifikasi.

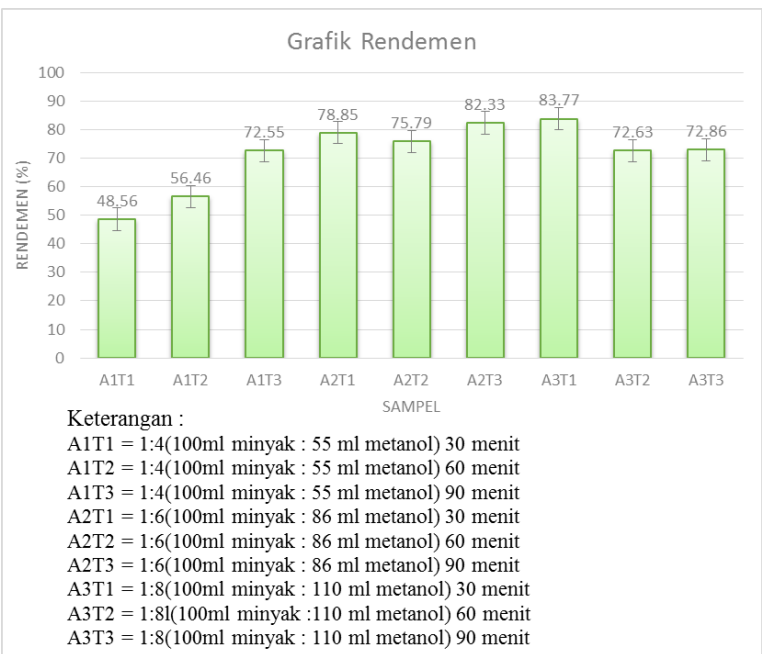

Gambar 3. Grafik Rata-rata Rendemen Biodiesel Minyak Biji Alpukat

$\begin{array}{rrrr}\text { Berdasarkan } & \text { grafik menunjukkan } \\ \text { bahwa adanya } & \text { keterkaitan antara }\end{array}$ perbandingan minyak dan metanol terhadap rendemen yang dihasilkan setelah melalui proses transesterifikasi dan pencucian menggunakan water washing. Dari grafik tersebut dapat dikatakan bahwasannya semakin banyak perbandingan antara minyak dan metanol saat proses transesterifikasi akan berpengaruh terhadap rendemen yang dihasilkan. Semakin lama waktu proses transesterifikasi akan berpengaruh terhadap rendemen yang dihasilka terbukti pada hasil pencucian sempel A3T1 (perbandingan metanol 1:8 dengan waktu 30 menit).

Rendemen tertinggi pada penelitian ini terdapat pada sampel A3T1 dengan komposisi perbandingan minyak dan metanol 1:8 dengan lama waktu reaksi transesterifikasi 30 menit sebesar 93,49 dengann rata - rata 83,77. Komposisi perbandingan minyak dan metanol serta waktu sangat berpengaruh terhadap nilai rendemen yang didapat.

Semakin tinggi konsentrasi katalis dapat meningkatkan konversi dan kecepatan reaksi transesterifikasi. Hal ini disebabkan karena dengan naiknya kosentrasi katalis akan semakin menurunkan energi aktivasi, sehingga meningkatkan jumlah molekul yang teraktifkan yang mengakibatkan kecepatan reaksi menjadi naik (Aziz et al., 2017).

Analisa berikutnya untuk membuktikan hasil penelitian merupakan perlakuan terbaik, sehingga dibutuhkan pengujian lanjut menggunakan uji statistik analisis ragam (ANOVA) dengan menggunakan uji $\mathrm{F}$ pada tingkat kepercayaan 
95\% dan 99\%. Berdasarkan hasil analisa sidik ragam menujunkkan bahwa perbandingan minyak dan metanol tidak mempunyai perbedaan yang nyata (non significant) hal ini dikarenakan $\mathrm{F}_{\text {hitung }}<\mathrm{F}_{\text {tabel }}$ pada taraf nyata 5\%, sehingga keragaman tersebut mempunyai notasi NS. Sedangkan untuk interkasi keduanya antara perbandingan minyak dan metanol serta waktu transesterifikasi mempunyai pengaruh sangat berbeda nyata karena $F_{\text {hitung }}>F_{\text {tabel }}$ pada taraf nyata $1 \%$. Interaksi antara keduanya yang memberikan pengaruh sangat beda nyata sehingga perlu dilakukan uji lanjut menggunakan DMRT (Duncan Multiple Rangen Test).

Berdasarkan hasil uji DMRT pada Tabel 2, menunjukkan bahwa hasil rendemen tertinggi dengan adanya perbedaan nyata pada perlakuan A3T1 (perbandingan 1:8). Pada penelitian ini rendemen tertinggi ada pada perbandingan minyak dan metanol 1:8 dengan waktu 30 menit. Semakin banyak variasi metanol maka semakin banyak biodiesel yang dihasilkan meskipun tidak signifikan.

Tabel 2. Hasil Pengujian DMRT (Duncan Multiple Rangen Test)

\begin{tabular}{|c|c|c|c|c|c|c|c|c|c|c|c|}
\hline $\begin{array}{l}\text { Perla } \\
\text { kuan }\end{array}$ & $\begin{array}{l}\text { Rata- } \\
\text { rata }\end{array}$ & 48,56 & 56,46 & 72,55 & 72,63 & 72,86 & 75,79 & 78,85 & 82,33 & 83,77 & Simbol \\
\hline$\overline{\mathrm{A} 1 \mathrm{~T} 1}$ & 48,56 & 0,00 & & & & & & & & & $\mathrm{~A}$ \\
\hline A1T2 & 56,46 & 7,9 & 0,00 & & & & & & & & $\mathrm{AB}$ \\
\hline A1T3 & 72,55 & 23,99 & 16,09 & 0,00 & & & & & & & B \\
\hline A3T2 & 72,63 & 24,07 & 16,17 & 0,08 & 0,00 & & & & & & $\mathrm{BC}$ \\
\hline A3T3 & 72,86 & 24,3 & 18,4 & 0,31 & 0,23 & 0,00 & & & & & $\mathrm{C}$ \\
\hline A2T2 & 75,79 & 27,23 & 19,33 & 3,24 & 3,16 & 2,93 & 0,00 & & & & $\mathrm{CD}$ \\
\hline A2T1 & 78,85 & 30,29 & 22,39 & 6,3 & 6,22 & 5,99 & 3,06 & 0,00 & & & D \\
\hline A2T3 & 82,33 & 33,77 & 25,87 & 9,78 & 9,7 & 9,47 & 6,54 & 3,48 & 0,00 & & $\mathrm{DE}$ \\
\hline A3T1 & 83,77 & 35,21 & 27,31 & 11,22 & 11,14 & 10,91 & 7,98 & 4,92 & 1,44 & 0,00 & E \\
\hline
\end{tabular}

\section{Uji Nyala Biodiesel Minyak Biji Alpukat}

Uji nyala merupakan angka yang menyatakan suhu terendah dari bahan bakar minyak yang terbakar, jika permukaan minyak tersebut didekatkan dengan nyala api. Titik nyala diperlukan untuk keperluan keamanan dalam penanganan minyak terhadap bahaya kebakaran. Hasil uji nyala dapat dilihat pada Tabel 3.

Tabel 3. Hasil Uji Nyala Biodiesel Minyak Biji Alpukat

\begin{tabular}{ccc}
\hline Perbandingan & Waktu & Suhu \\
\hline A1T1 & 59 detik & 86 \\
A1T2 & 43,5 detik & 85 \\
A1T3 & 53,5 detik & 86 \\
A2T1 & 38 detik & 81,5 \\
A2T2 & 37,5 detik & 88 \\
A2T3 & 40 detik & 89 \\
A3T1 & 66 detik & 88 \\
A3T2 & 40 detik & 84,5 \\
A3T3 & 41,5 detik & 90 \\
\hline
\end{tabular}

Uji nyala dilakukan dengan cara sampel biodiesel murni dipanaskan kemudian dituang ke wadah. Dalam penelitian ini menggunakan sendok makan sebagai wadahnya. Sendok tersebut didekatkan ke sumber api dimana menggunakan lilin yang kemudian ditunggu hingga sampel terbakar dan terjadi nyala api. Uji nyala tercepat adalah sampel perbandingan 1:6 sekitar 37 detik, sedangkan uji nyala terlama adalah sampel perbandingan 1:8 sekitar 60 detik. Banyak faktor yang mempengaruhi cepat lambatnya biodiesel terbakar salah satunya dari penyebaran api dari lilin. Hal tersebut menunjukkan bahwa semakin tinggi nilai titik nyala maka bahan bakar tersebut lebih aman karena tidak mudah terbakar.

\section{Karakteristik Biodiesel Minyak Biji Alpukat}

Karakteristik biodiesel bertujuan untuk mengetahui dan mengidentifikasi sifat suatu bahan yang dibandingkan dengan standar mutu biodiesel yang telah ditetapkan. Pada penelitian ini dilakukan uji karakteristik biodiesel pada perlakuan A3T1 (komposisi perbandingan 1:8 dengan waktu reaksi 30 menit). Jenis pengujian yang dilakukan pada penelitian ini yaitu, kadar asam, densitas, 
viskositas, nilai kalor, kadar metil ester (FAME), angka setana, bilangan iodin. Berikut ini hasil pengujian sampel biodiesel A3T1 ditunjukkan pada Tabel 4.

Tabel 4. Perbandingan Biodiesel Minyak Biji Alpukat dan Standart Biodiesel SNI 04-7182-2015

\begin{tabular}{lcc}
\hline \multicolumn{1}{c}{ Parameter } & $\begin{array}{c}\text { Standart } \\
\text { Biodiesel }\end{array}$ & $\begin{array}{c}\text { Biodiesel } \\
\text { Minyak Biji } \\
\text { Alpukat }\end{array}$ \\
\hline $\begin{array}{l}\text { Massa jenis } \\
\left(\mathrm{kg} / \mathrm{m}^{3}\right)\end{array}$ & $840-890$ & 967 \\
$\begin{array}{l}\text { Viskositas(cSt) } \\
\text { Bilangan Asam } \\
(\mathrm{mgKOH} / \mathrm{gr})\end{array}$ & $2,3-6,0$ & 4,71 \\
$\begin{array}{l}\text { Angka Iodin } \\
(\%-\text { Mass } 0,5\end{array}$ & Maks. 115 & 0,4 \\
$\begin{array}{l}\text { Angka setana } \\
\begin{array}{l}\text { Nilai kalor } \\
(\mathrm{MJ} / \mathrm{kg})\end{array}\end{array}$ & Minimal 51 & 8,10 \\
$\begin{array}{l}\text { Kadar Metil } \\
\text { Ester }(\%)\end{array}$ & Minimal 40 & 44,77 \\
\hline
\end{tabular}

Pengujian sampel A3T1 bahwasannya karakteritik yang sesuai dengan standar biodiesel 04-7182-2015 yaitu: viskositas, bilangan asam, angka iodin dan nilai kalor. Karakteristik yang tidak sesuai dengan standar SNI 04- 7182- 2015 ialah massa jenis, angka setana dan kadar metil ester.

Dibandingkan dengan penelitian sebelumnya, memiliki nilai bilangan asam yang tidak memenuhi standar SNI yaitu sebesar 2,04 sedangkan nilai viskositas relatif lebih rendah dibanding penelitian ini dan masih memenuhi standar SNI (Rachimoellah et al., 2009). Massa jenis pada penelitian tersebut ialah 863 sehingga memenuhi standar SNI berbeda dengan penelitian ini yang memiliki nilai jauh lebih tinggi yaitu 967. Untuk kadar metil ester pada penelitian ini lebih tinggi dibangding penilitian tersebut yaitu $48,02 \%$.

a. Densitas

Densitas atau massa jenis merupakan jumlah atau kuantitas massa suatu zat terhadap volumenya pada suhu tertentu. Densitas merupakan parameter yang digunakan untuk mengetahui keberhasilan dari proses pembuatan biodiesel. Pengukuran densitas dilakukan dengan metode ASTM D 1298 dengan suhu $40^{\circ} \mathrm{C}$ sehingga sampel yang digunakan dipanaskan terlebih dahulu sampai suhu yang sudah ditetapkan. Standar biodiesel berdasarkan SNI $04-7182-2015$ adalah 850 $-890 \mathrm{~kg} / \mathrm{m}^{3}$.

Sampel A3T1 pada penelitian ini densitas yang dihasilkan denga menggunakan metode pengukuran piknometer adalah 967 $\mathrm{kg} / \mathrm{m}^{3}$. Hal ini menunjukkan bahwa biodiesel yang dihasilkan, densitasnya tidak sesuai standar biodiesel.Tingginya massa jenis pada suatu biodiesel dikarenakan penggunaan katalis yang tidak terbuang sempurna pada saat pencucian.

b. Viskositas

Viskositas adalah sifat kekentalan dari bahan bakar. Umumnya bahan bakar harus memiliki viskositas yang relatif rendah agar mengalir dan menghasilkan pembakaran yang sempurna. Viskositas yang semakin tinggi pada bahan bakar akan menyebabkan bahan bakar tersebut sulit mengalir dan sulitnya pengkabutan pada mesin. Sebaliknya viskositas yang terlalu rendahakan menyebabkan terbentuknya sebuah gejala sehingga bahan bakar tidak bisa masuk kedalam silinder.

Hasil pengujian sampel A3T1 nilai viskositas adalah $4,71 \mathrm{cSt}$. Hasil dari nilai viskositas tersebut sesuai dengan standar biodiesel karena masih dalam rentan standar biodiesel yaitu $2,3-6,0 \mathrm{~mm}^{2} / \mathrm{s}$. Nilai viskositas tinggi dan rendahnya dipengaruhi oleh beberapa faktor diantaranya komposisi lemak biodiesel (metil ester) dan asam lemak yang beraksi dengan pereaktan.

c. Bilangan Asam

Bilangan Asam ialah jumlah $\mathrm{KOH}$ yang digunakan untuk menentralkan asam lemak dalam biodiesel. Rendahnya bilangan asam menunjukkan bahwa kandungan asam lemak bebas dalam biodiesel juga rendah. Apabila kandungan bilangan asam tinggi maka telah terjadi kerusakan akibat oksidasi selama penyimpanan (Lamria, 2006).

Angka asam merupakan indikator penting dalam pembuatan biodiesel, semakin rendah bilangan asam maka semakin sedikit asam lemak bebas yang terkandung didalam biodiesel (Padil et al., 2012). Nilai bilangan asam berbahan baku minyak biji alpukat sebesar $0,4 \mathrm{mgKOH} / \mathrm{gram}$. Nilai tersebut memenuhi standar SNI 04-7182-2015 biodiesel ialah sebesar 0,5 $\mathrm{mgKOH} / \mathrm{gram}$. Bilangan asam yang rendah atau sesuai dengan standar maka akan mencegah terjadinya penyumbatan pada injektor mesin yang dapat diakibatkan dari timbulnya kerak 
(Meisandi, 2013). Gambar 4 berikut adalah grafik rata-rata bilangan asam biodiesel minyak biji alpukat.

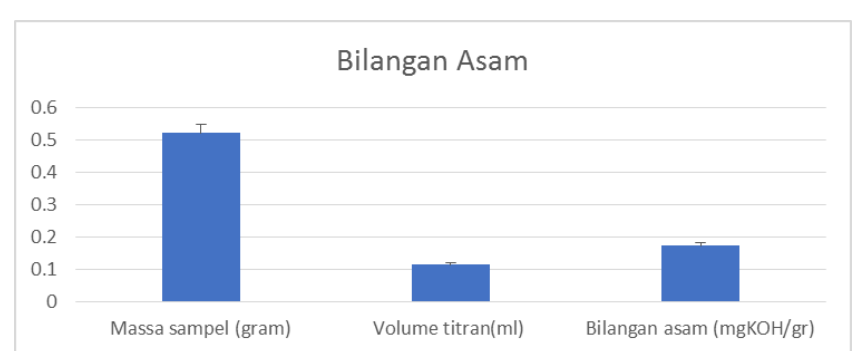

Gambar 4. Grafik Rata-rata Nilai Bilangan Asam Biodiesel Minyak Biji Alpukat

\section{d. Kadar Metil ester (FAME)}

Kadar metil ester merupakan angka yang menunjukkan besarnya kandungan ester didalam biodiesel. Semakin tinggi kandungan metil ester maka semakin baik kualitas biodiesel yang dihasilkan.

Kandungan kadar metil ester pada penelitian ini tidak memenuhi standar SNI 04 $-7182-2015$ yaitu minimal $96,5 \%$. hasil dari pengujian yaitu sebesar 94,05\%, salah satu faktor yang mempengaruhi rendahnya kadar metil ester adalah kurang optimal dalam proses pencucian, sehingga masih ada sisa pengotor dalam biodiesel tersebut, salah satu katalis yang tidak ikut terbuang pada proses pencucian dan menyerap kandungan metil ester. Terbukti dengan adanya endapan putih pada biodiesel pada saat proses penyimpanan.

e. Nilai Kalor

Nilai kalor merupakan energi panas yang dilepaskan ketika melakukan pembakaran sempurna tiap satuan massa bahan bakar. Nilai kalor dibedakan menjadi 2 macam, yaitu LHV (Lower Heating Value) dan HHV (Higher Heating Value). HHV merupakan nilai kalor pembakaran ditentukan ketika kandungan air produk pembakaran berupa cairan sedangkan LHV merupakan nilai kalor pembakaran dengan uap air akan tetap menjadi uap air (gas) hingga akhir proses pembakaran (Pratiwi et al., 2016).

Nilai kalor merupakan jumlah energi yang terlepas tiap satuan massa bahan bakar ketika berlangsungnya proses pembakaran yang sempurna. Pengukuran nilai kalor pada penelitian ini menggunakan metode pendekataan yang dilakukan oleh (Enweremadu and Alamu, n.d.) dengan pendekata nilai penyabunan dan bilangan iodin.
Hasil perhitungan nilai kalor biodiesel berbahan baku minyak biji alpukat sebesar $48,81 \mathrm{MJ} / \mathrm{kg}$ nilai tersebut sesuai dengan standar nilai kalor SNI biodiesel yaitu minimal $40 \mathrm{MJ} / \mathrm{kg}$. Nilai kalor digunakan untuk menghitung konsumsi bahan bakar yang dibutuhkan oleh mesin dalam suatu periode tertentu.

\section{f. Angka Setana}

Angka setana merupakan parameter penting dalam melihat kinerja minyak solar. Angka setana menunjukkan kualitas penyalaan bahan bakar tersebut (Lamria, 2006). Dibandingkan dengan penelitan Lamria (2006) yang berjudul Biodiesel Dari Minyak Biji The memiliki nilai angka setana memenuhi Standar SNI yaitu sebesar 51, pada penelitian tersebut nilai angka setana lebih tinggi dibanding penelitian ini yang masih dibawah standar SNI. Angka setana pada penelitian tersebut yaitu sebesar 54,04 sehinnga melebihi ketentuan dari standar $\mathrm{SNi}$ berbeda dengan peneltian ini yang memiliki nilai lebih rendah yaitu 44,77.

Penentuan angka setana yang dilakukan pada penelitian ini menggunakan metode pendekatan nilai bilangan penyabunan dan angka iodin. Nilai pendekatan indeks setana biodiesel minyak biji alpukat pada penelitian ini sebesar 44,77 dan dapat dikatakan tidak memenuhi standar biodiesel 04- 7182-2015 yaitu minimal sebesar 51 .

Angka setana yang tinggi pada suatu biodiesel berdampak buruk pada mesin diesel. Dampak yang ditimbulkan dari tingginya angka setana yaitu mudahnya terjadi proses pembakaran didalam silinder. Semakin kecil indeks setana maka semakin buruk kualitas biodiesel, karena waktu penundaan antara injeksi semakin lama.

\section{KESIMPULAN}

Minyak biji alpukat mengandung kadar FFA sebesar 0,87\%, dikarenakan kandungan FFAnya kurang dari $2 \%$ sehingga tidak perlu dilakukan proses esterifikasi sebelum dilanjutkan ke proses transesterifikasi. Hasil transesterifikasi berupa metil ester, sedangkan hasil sampingnya berupa gliserol. Pada proses pencucian menggunakan water washing, perbandingan separasi atau pemisahan di antara sampel, hanya sampel perbandingan 1:4 yang membutuhkan waktu lama sekitar 45 menit lebih lama dibanding sampel 
perbandingan 1:6 dan 1:8. Pengaruh perbandingan minyak dan metanol serta pengaruh waktu terhadap rendemen biodiesel adalah semakin banyak jumlah metanol yang digunakan, maka semakin banyak rendemen yang dihasilkan. Sampel dengan rendemen tertinggi ialah A1T3 sebesar 93,49\%. Hasil pengujian karakteristik biodiesel yang telah dilakukan, parameter yang sesuai dengan SNI 7182-2015 adalah viskositas 4,71 cSt, bilangan asam $0,4 \mathrm{mgKOH} / \mathrm{gr}$, angka iodin 8,10 gram/100gram dan nilai kalor 48,81 $\mathrm{MJ} / \mathrm{kg}$. Sedangkan parameter yang tidak sesuai adalah densitas $967 \mathrm{~kg} / \mathrm{m}^{3}$, angka setana 44,77 dan kadar metil ester 94,05\%.

\section{DAFTAR PUSTAKA}

Atadashi, I.M., 2015. Purification of crude biodiesel using dry washing and membrane technologies. Alex. Eng. J. 54:1265-1272. https://doi.org/10.1016/ j.aej.2015.08.005

Aziz, A., J. Subroto, \& V. Silpana. 2017. Aplikasi Modul Pendingin Termoelektrik Sebagai Media Pendingin Kotak Minuman. $J$. Rekayasa Mesin, 10. https://doi.org/10.32497/rm.v10i1.778.

Badan Pusat Statistik. 2018 [WWW Document]: https://www.bps.go.id/ publication/2019/10/07/184660536395 5649c9f6dd6d/statistik-tanaman-buah--buahan-dan-sayuran-tahunanindonesia-2018.html

(accessed 6.23.20).

Enweremadu, C.C., \& O.J. Alamu n.d. Development and characterization of biodiesel from shea nut butter. Int. Agrophysics, 24: 29-34.

Hartono, R. 2014. Intensifikasi Biodiesel Dari Minyak Jelantah Dengan Metode Interesterifikasi Dan Pemurnian Dry Washing. J. Teknol. Pengelolaan Limbah, 16.

Lamria, I.R. 2006. Biodiesel dari minyak biji teh. J. Kim. Dan Kemasan 0, 32-38. https://doi.org/10.24817/jkk.v0i0.3283.

Meisandi, C.T. 2013. Pembuatan Biodiesel Dari Biji Alpukat (Persea americana) Melalui Proses Transesterifikasi.
Padil, P., S. Wahyuningsih, \& A. Awaluddin. 2012. Pembuatan Biodiesel dari Minyak Kelapa melalui Reaksi Metanolisis Menggunakan Katalis CaCO3 yang dipijarkan. J. Nat. Indones, 13:27-32. https://doi.org/10. 31258/jnat.13.1.27-32.

Pratiwi, N., M. Masriani, \& I. Prihatiningtyas. 2016. Perbandingan Proses Esterifikasi dan Esterifikasi -Trans-esterifikasi dalam Pembuatan Biodisel dari Minyak Jelantah. Seminar Nasional Tek. Kim. Kejuangan 0, 4.

Produksi Biodiesel Dari Minyak Jelantah Menggunakan Katalis Heterogen Cangkang Bekicot (Achatina Fulica) Dengan Metode Pencucian Dry Washing | ROTOR, n.d.

Rachimoellah, H.M., D.A. Resti, A. Zibbeni, \& I.W. Susila. 2009. Production of Biodiesel through Transesterification of Avocado (Persea gratissima) Seed Oil Using Base Catalyst. J. Tek. Mesin, 11: 85-90. https://doi.org/10.9744/ jtm.11.2.pp. 85-90.

Rachmanita, R.E. 2019. The High Capacitance for Electrode Structure of Interdigital Capacitor Thin Film Models. SNRU J. Sci. Technol., 11: 5563.

Rachmanita, R.E., M. Suweni Muntini, S. Thawankaew, W. Chao-Moo, A. VoraUd, \& T. Seetawan. 2018. Fabrication and characterization of interdigital capacitors thin film by DC magnetron sputtering for measuring the permittivity of crude oil. Mater. Today Proc., The 3rd International Conference on Applied Physics and Materials Applications (ICAPMA 2017), 31 May-2 June 2017 5, 15192 15197.

https://doi.org/10.1016/j.matpr.2018.04 .081 .

Rejeki, S. 2009. Pengaruh Metode Pencucian Pada Pembuatan Biodiesel. J. Tek. Kim., 3.

Risnoyatiningsih, S. 2012. Biodiesel From Avocado Seeds By Transesterification Process. J. Tek. Kim., 5: 345-351. https://doi.org/10.33005/jurnal_tekkim. v5i1.136. 
Ritonga, M.Y., D.H. Sihombing, \& A.R. Sihotang. 2013. Pemanfaatan Abu Kulit Buah Kelapa Sebagai Katalis Pada Reaksi Transesterifikasi Minyak Sawit Menjadi Metil Ester. J. Tek. Kim. USU, 2:17-24. https://doi.org/ 10.32734/jtk.v2i4.1486.

Salamah, S. 2017. Kinetika Reaksi Esterifikasi Minyak Biji Kapuk Pada Pembuatan Biodiesel. Kinet. Reaksi Esterifikasi Miny. Biji Kapuk Pada Pembuatan Biodiesel.
Tamako, P.D. 2017. Potensi minyak biji alpukat (Persea americana) sebagai bahan baku pembuatan biodiesel (diploma). UIN Sunan Gunung Djati Bandung.

http://digilib.uinsgd.ac.id/5465/10/10_ daftarpustaka.pdf. 